\title{
FERRAMENTAS DA WEB 2.0, CIDADANIA E PARTICIPAÇÃO: O CASO DO WEBSITE VOTE NA WEB
}

\author{
Caroline Kraus Luvizotto, Lucas Arantes Zanetti, Gabriela Ramos Teixeira \\ Universidade Estadual Paulista - UNESP, Faculdade de Arquitetura, Artes e Comunicação - FAAC, Bauru/SP. \\ E-mail: caroline@faac.unesp.br \\ Financiamento: CNPq, UNESP/PROPe e FUNDUNESP
}

\section{RESUMO}

Muitas ações de caráter político-social se fortaleceram e se potencializaram a medida em que a internet deu suporte a elas, utilizando sua arquitetura em rede para disseminar informação e promover a participação e a discussão coletiva. Com o intuito de compreender como as ferramentas da internet contribuem para esse novo cenário de participação política e social no Brasil, identificamos um website caracterizado por ser um canal de participação de cidadãos em questões governamentais: o Vote na Web. Este estudo objetiva descrever o website Vote na Web no contexto da participação político-social buscando verificar sua abrangência e performance e analisar o potencial das tecnologias digitais no revigoramento da cidadania. A pesquisa aqui apresentada caracteriza-se por ter como vertente metodológica uma abordagem qualiquantitativa. Concluímos que o website possui limitações e que as ferramentas on-line não são utilizadas em sua potencialidade. Porém, o website favorece a participação político-social.

Palavras-chaves: Participação político-social; Internet; Cidadania; Vote na Web.

TOOLS OF WEB 2.0, CITIZENSHIP AND PARTICIPATION: THE CASE OF WEBSITE VOTE NA WEB

\begin{abstract}
Many political and social character actions have been strengthened and worsened the extent that the internet has given support to them, using your architecture network to disseminate information and promote participation and collective discussion. In order to understand how Internet tools contribute to this new scenario of political and social participation in Brazil, we identified a featured website to be a citizens' participation in government affairs channel:. Vote on the Web. This study aims to describe the website Web Vote in the context of political and social participation in order to verify its scope and performance and analyze the potential of digital technologies in the strengthening of online citizenship. The research presented here is characterized by having as a methodological aspect a qualitative and quantitative approach. We conclude that the website has limitations and that online tools are not used in their potentiality. However, the website promotes political and social participation.
\end{abstract}

Keywords: Political and social participation; Internet; Citizenship; Vote na Web. 


\section{INTRODUÇÃO}

A participação social é uma ação coletiva que possui em sua gênese uma série de características, dentre as quais, podemos destacar suas estratégias de ação, sua organização, a historicidade, os laços e identidades compartilhadas. Essas características somadas à um projeto de sociedade é que levam os atores sociais a se aproximarem dessas ações coletivas e atuarem ativamente ou ocasionalmente junto aos movimentos sociais, aos espaços de deliberação política e aos mais diversos contextos onde se faz necessária uma ação democrática e cidadã.

Muitas ações de caráter político-social se fortaleceram e se potencializaram a medida em que a internet deu suporte a elas, utilizando sua arquitetura em rede para disseminar informação e promover a discussão coletiva. Portanto, compreende-se a importância fundamental da internet como ferramenta para disseminação de conteúdos informacionais de caráter político e social, bem como, como suporte para organizar ações coletivas.

Os recursos da web 2.0 facilitaram a criação e a circulação de conteúdos aos usuários da internet, que podem atuar como leitores, autores, produtores e editores de conteúdo informacional multimídia. O usuário não é mais pensado como agente passivo, mas como desenvolvedor de conteúdo. A segunda geração de ferramentas on-line potencializa as formas de publicação, compartilhamento e organização de informações, além de expandir os espaços para a colaboração entre os participantes. Reforça a promessa de criação de inteligência coletiva, ou construção coletiva do conhecimento. Por meio da interação, comunidades formadas em torno de interesses específicos poderão apoiar uma causa, discutir temas individuais ou de relevância coletiva, levar a opinião pública à reflexão e disseminar informações políticas e sociais (VALENTE; MATTAR, 2007).

As ferramentas web 2.0 estão organizando e fomentando o desenvolvimento de novas redes sociais virtuais, à medida que são reduzidos os custos da mobilização de atores sociais. A ação política através das tecnologias "torna-se mais barata, rápida e por consequência mais acessível a grupos que não fazem parte do sistema político institucionalizado", segundo Pereira (2011, p. 14). As redes que integram essa lógica possuem potencial articulador e mobilizador e, segundo Scherer-Warren (2006, p. 115), "por serem multiformes, aproximam atores sociais diversificados - dos níveis locais aos mais globais, de diferentes tipos de organizações - e possibilitam o diálogo da diversidade de interesses e valores".

Diversos questionamentos surgem diante do uso crescente da internet como mecanismo de apoio a participação política e social e a deliberação on-line: qual será o impacto da internet sobre a vida política das sociedades contemporâneas? E como ela afetará a representação e a participação da sociedade civil nos contextos políticos em nosso país?

A partir destas indagações e com o intuito de compreender como as ferramentas da internet contribuem para esse novo cenário de participação política e social no Brasil, identificamos um website caracterizado por ser um canal de participação de cidadãos em questões governamentais, objetivando fortalecer a luta pela cidadania e justiça social: o Vote na Web ${ }^{1}$.

Este estudo objetiva descrever o website Vote na Web no contexto da participação político-social buscando verificar sua abrangência e performance, e analisar o potencial das tecnologias digitais no revigoramento da cidadania.

\section{METODOLOGIA}

Esta pesquisa caracteriza-se por ter como vertente metodológica uma abordagem qualiquantitativa. Fazemos uso de métodos descritivos característicos da abordagem quantitativa para apresentar de forma gráfica e estruturada os dados produzidos. Elementos que não estavam adequados para uma abordagem quantitativa foram direcionados para a abordagem qualitativa. Inicialmente foram construídos os conceitos de participação, participação on-line e ferramentas

\footnotetext{
${ }^{1}$ Disponível em www.votenaweb.com.br
} 
web 2.0. A partir da compreensão desses conceitos foi efetuada a descrição do website VotenaWeb e a análise de suas ferramentas no contexto da participação.

A coleta de dados no website foi realizada durante os meses de março, abril e maio de 2015, com o objetivo geral de descrever a estrutura, caracterizar conteúdos e obter subsídios para identificar a função oficial da proposta do website para avaliar o seu potencial. A coleta constituise de um total de 29 imagens, dezenas de ferramentas e material postado no website.

\section{RESULTADOS}

O VotenaWeb se apresenta como um site de engajamento cívico e apartidário, que tem como objetivos aumentar a polarização da sociedade, e se compromete em levar os resultados da participação civil ao Congresso. Foi criado em novembro de 2009 pela Webcitizen, empresa que tem como foco a criação de canais de participação cidadã. $O$ site, além de tornar público projetos de lei do Congresso Nacional do Brasil possibilita que o cidadão vote, simbolicamente, se concorda ou não com as propostas dos parlamentares.

Uma de suas principais características são os resumos apresentados, formulados por analistas - a partir do texto do projeto de lei original - que buscam traduzir os termos utilizados para uma linguagem mais próxima a do público. Quando a lei passa por votação na Câmara e no Senado o site apresenta uma comparação entre o voto dos legisladores e dos usuários.

O Vote na web pretende ser um portal interativo, informativo, participativo e utiliza ferramentas da web 2.0 para cumprir sua proposta. Seu design é simples e intuitivo, de modo que o os usuários não possuem grandes dificuldades e obstáculos para utiliza-lo. As informações são colocadas de maneira objetiva, sem excesso de informação e ferramentas são disponibilizadas para agilizar o acesso, caso o usuário esteja procurando por uma lei ou parlamentar específico. Após um login, que pode ser feito através de cadastramento ou por meio das redes sociais Facebook ou Google+, pode navegar livremente pelo site, e utilizar todos seus recursos. A figura 1, a seguir, apresenta o website. 

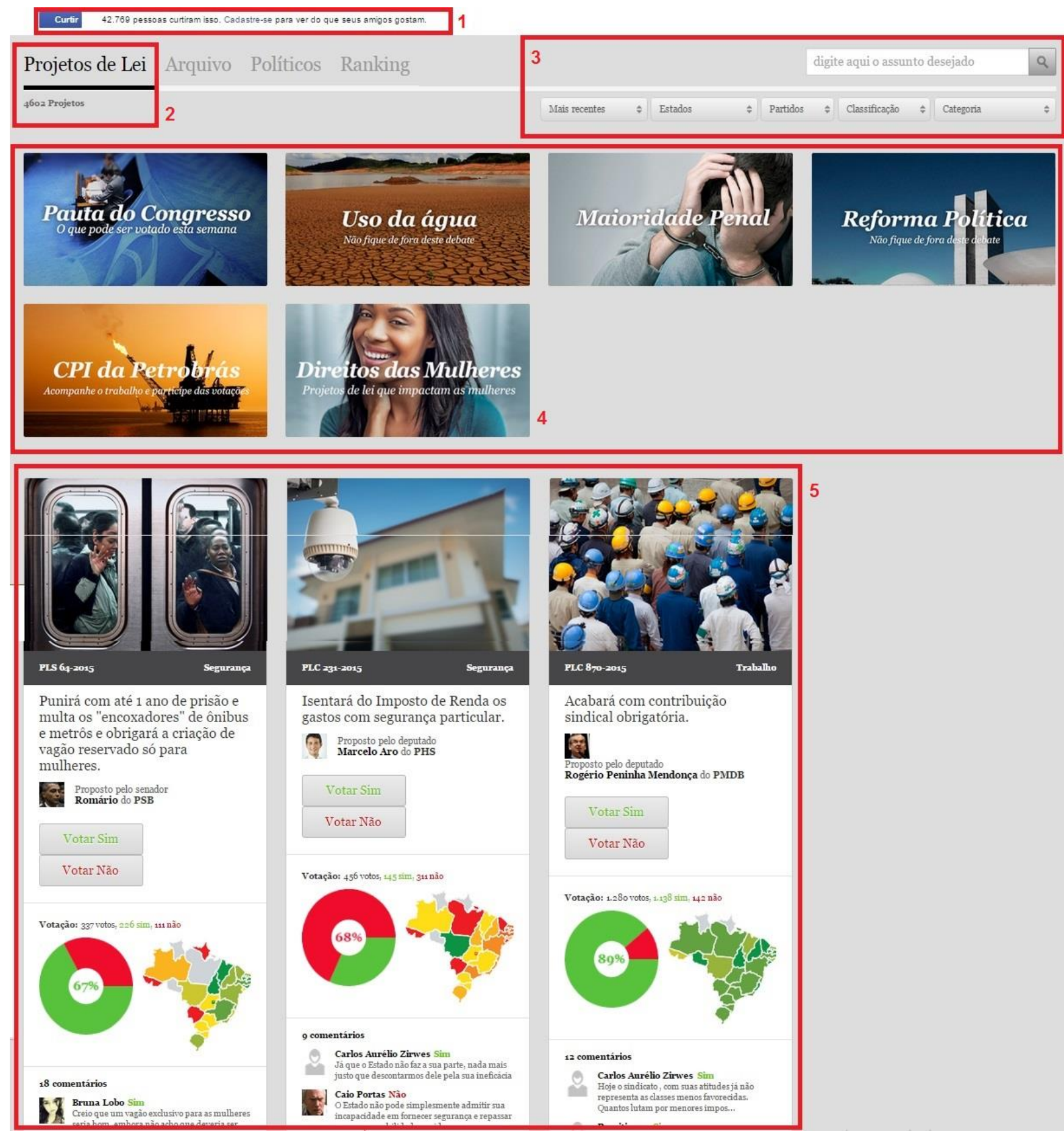

Figura 01. Aba dos projetos de lei, filtros e hiperlinks do VotenaWeb Fonte: http://www.votenaweb.com.br/ Acesso em: 20/04/2015

Na plataforma, há um local onde é possível "curtir" o Vote na web no Facebook e receber as notificações do portal via rede social, conforme mostra o item 1 da figura 1 . Também é possível acessar um link que direciona o usuário para todos os projetos de lei que estão tramitando na Câmara dos deputados e no Senado Federal, onde ele pode votar "sim" caso concorde, "não" caso discorde e também pode justificar sua escolha e interagir com outros usuários, de modo a compartilhar suas ideias, construir seu pensamento ou até mesmo discordar, criticar e até hostilizar as pessoas que ali comentaram, conforme mostra o item 2 da mesma figura.

No item 3 da figura 1, se encontram a ferramenta de busca, onde o usuário pode pesquisar qualquer projeto, tema de interesse ou parlamentar de modo objetivo em todo site, e a 
ferramenta que possibilita a seleção de projetos específicos através de filtros. São 5 filtros disponíveis que podem ser combinados para uma busca específica.

A primeira é a opção de ordem de visualização selecionada, podendo ser: "mais recentes", "apenas do senado", "apenas da câmara", "mais polêmicos", "mais votados" e "mais comentados". Também é possível selecionar os projetos por estados e partidos políticos. Outro filtro permitido é por classificação, que é dada pelos próprios usuários, que analisam a qualidade do Projeto de Lei, podendo ser: "urgente", "relevante", "corajoso", "inviável", "irrelevante" e "sem noção". O último filtro trata das categorias, que são divididas entre temas de relevância social, sendo eles: administração pública, ambiente, aposentados, cidade, consumidor, criança e adolescente, cultura, drogas, economia, educação, energia, esporte, homenagem, internet, justiça, necessidades especiais, saúde, segurança, trabalho e transporte.

Já o item 4 da figura 1 mostra a ferramenta de hiperlinks. Quando o usuário clica na foto, é direcionado para conjuntos de projetos que estão sendo muito debatidos no atual momento pela sociedade, como a questão da maioridade penal e a crise hídrica, permitindo aos internautas escolherem o tema de seu interesse.

Abaixo das ferramentas já explicadas, a plataforma coloca todos os projetos de lei, organizados de maneira temporal, dos mais recentes para os mais antigos, conforme ilustra o item 5 da figura 1. Além de votar, é possível clicar no projeto para entendê-lo com mais detalhes e novas ferramentas surgem, como por exemplo, a ferramenta de votar e comentar o projeto de lei.

\section{DISCUSSÃO}

O Vote na Web, logo em sua página inicial, disponibiliza um vídeo onde resume todo funcionamento do site, seus objetivos, as ferramentas e como utiliza-las, por meio de um tour pela plataforma. É mais uma forma de utilizar diversas mídias em uma plataforma da web 2.0, que facilita o acesso para os usuários que não possuem familiaridade com a internet.

Uma de suas principais características são os resumos apresentados, formulados por analistas - a partir do texto do projeto de lei original - que buscam traduzir os termos utilizados para uma linguagem mais próxima a do público. Quando a lei passa por votação na Câmara e no Senado o site apresenta uma comparação entre o voto dos legisladores e dos usuários.

Um ponto importante da arquitetura do website VotenaWeb é que ele permite que se visualize a computação dos votos em um parâmetro geral dos usuários, mas também divididos em categorias de gênero, idade e estado. Além dessas possibilidades, há um mapa do Brasil com a divisão de votos por estado que apresenta as diferenças da votação por escala de cores. Outros aspectos da arquitetura do referido site podem ser citados, como por exemplo, a divisão dos projetos de lei apresentados em categorias, como, economia, saúde, trabalho, cidades, cultura, esporte, transporte, entre outras. No site, também há duas ferramentas de busca, por filtros préestabelecidos, ou por palavras-chave.

A interface do VotenaWeb propõe ao usuário uma dinâmica de acesso intuitiva e didática. A maneira como as ferramentas são dispostas ajuda a despertar interesse pelo o site. A ferramenta de comentários e votos também é um meio que possibilita a participação dos cidadãos. Meramente pelos números de comentários não conseguimos analisar se de fato todos comentários são participativos, pois há comentários que não possuem conteúdo, porém é essa ferramenta que dá voz ao cidadão, mesmo que muitas vezes ela não seja usada para esse fim. É importante ressaltar que os comentários dependem muito da subjetividade e engajamento de cada indivíduo.

A descrição do website apresenta as limitações desse meio de comunicação, e indica que devemos discutir criticamente quais são os avanços que, de fato, a internet e as ferramentas Web 2.0 proporcionam no campo da cidadania e da democracia em nosso país, levando em conta nosso histórico de lutas políticas, organização da sociedade civil, entraves e limites de acesso a internet 
pela população brasileira e a abrangência dos meios de comunicação mais tradicionais, como a televisão, o rádio e a mídia impressa.

A partir das leituras, dos dados levantados e das discussões promovidas ao longo da pesquisa, foi adotada a perspectiva de que a internet e as ferramentas da Web 2.0 são um novo espaço comunicacional, que possibilita novos meios de acesso à informação e que pode ser apropriado pelos cidadão de diversas formas. É fato que tais ferramentas já produzem impactos na sociedade contemporânea, nas relações humanas, na organização social e no exercício da cidadania, porém o mais importante é que um canal interativo e de fácil acesso foi aberto com potencial para promover a cidadania, e a politização através da informação e da participação.

Existem alguns pontos que demandam uma reflexão mais profunda e crítica acerca da participação política na internet, crucial para entender o VotenaWeb. Conforme defendem alguns autores (BRUNDIDGE e RICE, 2009), tais ferramentas são utilizadas para informação de maneira mais efetiva por aqueles que já possuíam a prática de se informarem no meio offline e não implica um engajamento ou interesse político por si só. Nesse sentido, sendo a internet um espaço amplo, com infinitas informações e inúmeras ferramentas e oportunidades, ela pode ser ou não apropriada e utilizada para a cidadania como forma de participação e deliberação política, assim como já ocorre com os espaços existentes no meio offline. O fato de a internet existir não implica, necessariamente, que ela será usada de maneira adequada e nem que o usuário buscará se informar melhor sobre as questões políticas e sociais, nem que usará as ferramentas da comunicação em rede para exercer uma participação cidadã nas questões políticas de seu país. Além disso, a internet agrega em si todas as ideologias, formas de pensamentos e causas a ser defendidas, se tornando um reflexo da vida off-line, sendo que o indivíduo pode encontrar facilmente informações e argumentos que justifiquem e reforcem o que ele já pensa sobre determinada questão ou lei.

Por ser um ambiente onde as pessoas podem se expressar quase livremente, também é possível encontrar muitas informações que não são verdadeiras, discursos de ódio, tentativas de calúnia e difamação contra pessoas públicas e fatos distorcidos de maneira escancarada, o que pode muitas vezes atrapalhar uma compreensão real sobre os fatos. Ainda assim, justamente por ser livre, da mesma forma que inverdades podem ser publicadas elas podem ser mais facilmente contestadas e refutadas por outros usuários, com mais meios de consulta e apuração. Por isso, para maior efetividade do potencial informativo e cidadão da Web 2.0, é preciso que os cidadãos sejam educados a utilizar a rede e se apropriar de seus conteúdos de maneira consciente e buscando locais com credibilidade.

Sobre o potencial do VotenaWeb, é importante ressaltar, em primeiro lugar, a proposta cidadã do portal. A plataforma parte de uma iniciativa privada e é mantida por profissionais de diversas áreas do conhecimento, que busca na democracia digital formas de promoção da cidadania. A proposta do site é "fortalecer a democracia no mundo", promovendo a politização social por meio do acompanhamento do trabalho político no congresso e divulgando informações sobre a política nacional. A aposta na interatividade e o uso intuitivo e simplificado das ferramentas da Web 2.0 como forma de disseminação da informação talvez seja a maior virtude do portal.

\section{CONSIDERAÇÕES FINAIS}

As plataformas on-line devem ser pensadas e programadas de maneira que auxiliem as interações entre os sujeitos. Portanto, além de permitir a livre conversação entre usuários, elas devem fornecer ferramentas que auxiliem no processo de participação. Essas ferramentas relacionam-se intimamente com a arquitetura do site e com a informação disponibilizada para fomentar o debate, já que o participante também precisa ter acesso a informações que permitam a crítica e a tomada de decisão. As tecnologias da web 2.0 auxiliam o processo de participação 
política-social se forem utilizadas em sua totalidade, usando todo o potencial das ferramentas de interação e construção coletiva do conhecimento.

Concluímos que o website possui limitações e que as ferramentas on-line não são utilizadas em sua potencialidade. Mas, a partir de um contexto de cidadania e de participação on-line é possível verificar que a arquitetura do website favorece a participação, mesmo sem o engajamento cívico, e que os processos comunicativos e interativos inerentes à essa plataforma on-line são um passo em direção a uma prática cidadã mais ampla.

\section{REFERÊNCIAS}

BRUNDIDGE, J.; RICE, R. E. Political engagement and exposure to heterogeneous political discussion: Do the (information) rich get richer and the similar get more similar? In A. CHADWICK; P. N. HOWARD. The handbook of internet politics. London and New York: Routledge, 2009.

PEREIRA, M. A. Internet e mobilização política - os movimentos sociais na era digital. In: IV Encontro da Compolítica, 2011, Rio de Janeiro. Anais do IV Encontro da Associação Brasileira de Pesquisadores em Comunicação e Política, 2011.

SCHERER-WARREN, I. Das mobilizações às redes de movimentos sociais. Sociedade e Estado, v. 21, n. 1, p. 109-130, 2006. https://doi.org/10.1590/S0102-69922006000100007

VALENTE, C.; MATTAR, J. Second Life e Web 2.0 na educação: o potencial revolucionário das novas tecnologias. São Paulo: Novatec Editora, 2007. 